\title{
DESIGN AND OPTIMIZE A NOVEL ERGONOMIC SHOULDER OF UPPER LIMB REHABILITATION ROBOT
}

\section{THANH-TRUNG NGUYEN ${ }^{1 *}$, NGOC-LINHTAO ${ }^{2 *}$, VAN-TINH NGUYEN ${ }^{3 *}$, XUAN-THANH TRINH $^{4}$, VAN-THIEN DANG ${ }^{5}$, TUNG-HIEP DINH ${ }^{6}$, MINH-HOANG BUI ${ }^{7}$, QUANG-HUY BUI ${ }^{8}$, DUY-PHUC PHAM $^{9}$, NGOC-TAM BUI ${ }^{10^{*}}$, DAI WATANABE ${ }^{11}$ \\ $1^{*}, 2^{*}, 3^{*}, 4,5,6,7,8,9,10^{*}$ School of Mechanical Engineering, Hanoi University of Science and Technology,}

No.1 Dai Co Viet Rd, Hanoi, Vietnam

${ }^{11}$ College of Systems Engineering and Science, Shibaura Institute of Technology, Tokyo 135-8548, Japan

\begin{abstract}
Réhabilitations robots are topics that many researchers are interested in. Currently, most of the upperlimb rehabilitation robots use hinge joints to simulate human shoulder joints. This ensures that the robot shoulder joints have the same structure as the ball joints, or the ball joints are capable of lifting / lowering around a center like the famous Armin III model. However, in fact, the shoulder joint orbitis not a circle or a point, which leads to dis comfort for the patient during exercise. This study proposes to improve the shoulder joint design of the upperlimb rehabilitation robot to ensure the trajectory of the robot shoulder center coincides with the trajectory of the human shoulder joint. First, aproposal to design a new robot shoulder joint to have a flexible operating trajectoryaccording to the human shoulder joint willbe made. Next, the kinematic calculations, as well as optimizing the essential dimensions of the structure to ensure continuity, avoid sudden changes between consecutive points on the shoulder joint trajectory. After that, the shoulder joint structure to meet the above model was built. The process of optimization and simulation of the kinematic problem shows that the proposed robot shoulder joints can follow to the shoulder joints of the human arm, the total deviations in the $x$ and $y$ directions of the robot shoulder and the human shoulder joints in the whole The trajectoryis $0.0028 \mathrm{~mm}$ and 0.0115 , respectively.
\end{abstract}

KEYWORDS: Ergonomic, Upper Limb Rehabilitation Robot, Kinematic, Shoulder, Human Arm

Received: Jun 10, 2020; Accepted: Jun 30, 2020; Published: Aug 04, 2020; Paper Id.: IJMPERDJUN2020613

\section{INTRODUCTION}

Stroke is a neurological disease, and itis the leading cause of disability. The number of people, affected by stroke, is increasing in both developed countries such as in the EU [1], in the United State [2]... as well as developing countries like Vietnam, Thailand, One common symptom of stroke is acute hemiparesis that affects the upper or lower extremities. By using the rehabilitation method, the arm's sensor imotoris positive effects [3]. The key factors that contribute to the effectiveness of the rehabilitation process are intensive, long duration, repetitive, and task-oriented [4,5].

Manualre habilitation methods contain some disadvantages such as labor-intensive, lack of repetition, challenging to measure the progress of the practitioner. By using robots, the disadvantages mentioned above may be over comed. Exercises canbe automate dusing robots and duration as well as the number of exercises can be increased. Also, patient-cooperative controllers also help the training process increase the intensity of training. Requests for repetition of exercises can also be easily solved by robot. However, the requirement of task-oriented exercises often need robots with multiple Degrees of Freedom (DoF). Robots with such structure will help the 
patient'sarms move flexibly in the space for Activities of Daily Living (ADL), including eating, drinking, combing, dressing, and other essential activities.

Currently, there are many studies related to robot applications in rehabilitation. These robots are dividedintotwo main categories: end-effector and exoskeleton. End-effector-based robots connectwith patients 'arm at hand or forearm. They focus on controlling the position and orientation of end point. Many groups have been developing these kinds of robots, as in the ref. [8], MIT Manus [9], the Mirror Image motion Enabler [10].A great advantage of end-effector-based robots is that they can be easily adjusted to different arm lengths. The main disadvantage of this type isthat the arm posture, as well as the torque control joint, are not fully controlled. This results in a Range of Motion (RoM) of joints are limited.

The above limitation of end-effector robots can be handled by exoskeleton-based robots. The structures of the exoskeleton robot resemblea human arm'sanatomy; the robot's axes aredesigned to coincide with the human arm axes. The advantage of this robot type compared to the end-effect or one is that the arm postures are entirely determined. This isaccomplished by the moments thatact on each joint of the human arm are separately and controlled, and hyper extension of the joints can be destroyed by mechanical stop mechanisms. Thus, it allows larger RoM to perform the ADL better. The ability to control the moment in independent joints isalso an essential feature. For example, when the human's elbow flexors are spastic. The movements of the right elbow joint must not generate force or moment at the shoulder joint. This can be guaranteed by an exoskeleton, but not by an end-effector one. Some examples of the exoskeleton robots can be listed as in Ref (s) [11-15].

For exoskeleton-based rehabilitation robots, the coaxial requirement between the robot joint and the human joint is easy to fulfill with simple joints such as the elbow joint, but very difficult for complicated joint like the shoulder joint. A wide spread hypothesis to simplify the shoulder joint structure is that it is equivalent to a 'ball and socket type' [16-18]. This assumption leads to misalignment between the robot and the human and makes patients be uncomfortable during exercise.

The reason for the incompatibility between the human shoulder joint and the robot shoulder joint is the complex structure of the human shoulder joint. During arm elevation movement, the humerus head (HH) moves vertically [19]. There are several solutions to over come this drawback by adding 1 [20], 2 [21] or 3 [22] passive joints. The addition of these passive DoF creates comfort for the patient's shoulder, but it can make it challenging to assess statically. Another solution is to add active DoF as in Armin II or the structure of MGA-Exoskeleton. However, these structures have the disadvantage of high complexity. The Armin III model is now very well-known. In this model, by deflecting the elevation actuator, the robot shoulder joints move on an arc approximately the same as the moving trajectory of the HH point. With this structure, the point of $\mathrm{HH}$ robot isstill not identical to that of humans. In this paper, we propose a new robot shoulder joint model that ensures the robot shoulder joints coincide with the human shoulder joints. The rest of the paper is structured as follows: Section II shows the proposal ergonomic shoulder for the robot; the results of the optimal dimension, as well as the forward kinematic, are presented in section III; the final section is the conclusion. 

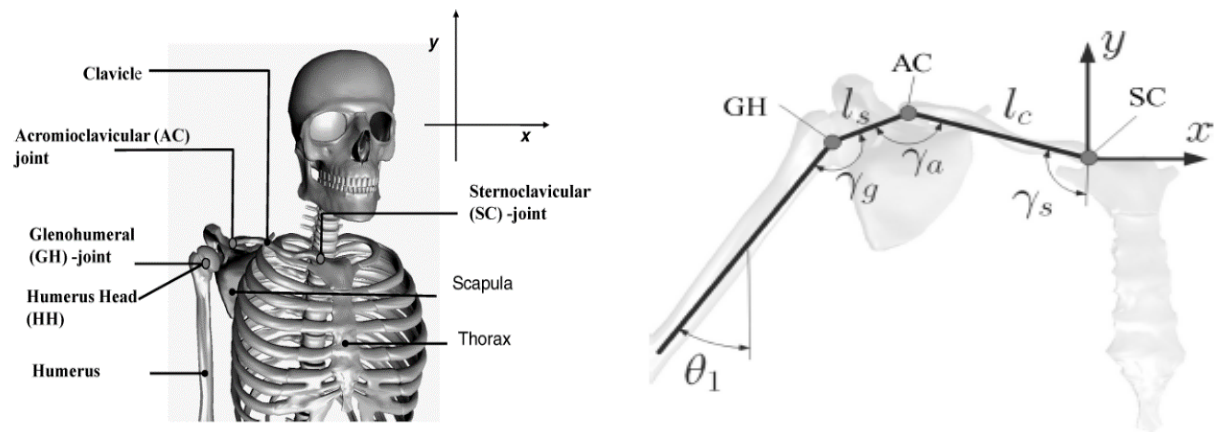

Figure 1: (A) Humanshoulder Joint; (B) Joint Angles of the Human Shoulder [19].

\section{PROPOSAL THE NOVAL SHOULDER STRUCTURE}

\subsection{Human Shoulder Structure}

$\gamma_{a}=f\left(\theta_{1}\right)$

$=\left\{\begin{array}{c}0^{o} \text { wit } \square 0^{o} \leq \theta_{1} \leq 70^{o} \\ 35\left(10\left(\frac{\theta_{1}}{80^{o}}\right)^{3}-15\left(\frac{\theta_{1}-70^{o}}{140^{o}-70^{o}}\right)^{4}+6\left(\frac{\theta_{1}-70^{o}}{140^{o}-70^{\circ}}\right)^{5}\right) \text { wit } \square 70^{o} \leq \theta_{1} \leq 150^{o} \\ 35^{\circ} \text { wit } \square 150^{o} \leq \theta_{1} \leq 180^{o}\end{array}\right.$

$\gamma_{s}=f\left(\theta_{1}\right)=\left\{\begin{array}{c}15\left(10\left(\frac{\theta_{1}}{80^{o}}\right)^{3}-15\left(\frac{\theta_{1}}{80^{\circ}}\right)^{4}+6\left(\frac{\theta_{1}}{80^{\circ}}\right)^{5}\right) \text { wit } \square 0^{o} \leq \theta_{1} \leq 80^{o} \\ 15^{o} \text { wit } \square 80^{o} \leq \theta_{1} \leq 140^{o} \\ 15^{o}+9\left(10\left(\frac{\theta_{1}-140^{o}}{180^{o}-140^{o}}\right)^{3}-15\left(\frac{\theta_{1}-140^{o}}{180^{o}-140^{o}}\right)^{4}+6\left(\frac{\theta_{1}-140^{o}}{180^{o}-140^{o}}\right)^{5}\right) \text { wit } \square 140^{o} \leq \theta_{1} \leq 180^{o}\end{array}\right.$

$\gamma_{g}=f\left(\theta_{1}\right)=\theta_{1}-\gamma_{a}\left(\theta_{1}\right)-\gamma_{s}\left(\theta_{1}\right)$

The shoulder joint structure is made up of a group of four main bones including the humerus, scapula, clavicle and breast bone (thorax). These bones are connected by 3 joints: the glenohumeral (GH joint) connecting humerus and scapula; acromioclavicular joint (AC joint) connecting scapula and clavicle; Sternoclavicular Joint (SC joint) links clavicle and thorax. Elevationmovement of humerusis born by rotation movement of humerus around GH joint; scapula around AC joint and clavicle around SC joint. With this mechanism, the movement of HH is not the 'ball socket type' or on spherical. To control the robot with the goal of creating a sense of comfort for the patients, knowingHH's motion orbitis essential.

According to [19], in order to simplify, qualify and derive the model of the coupling between the arm elevation angle and horizontal displacement of human arm. There are some assumptions as following :

- Individuals with the same body have the HH motion.

- $\quad$ Training and age do not influence the HH movement pattern.

- The additional external mass does not affect the position of the scapula nor the position of the HH.

- The pointing angle of internal / external shoulder rotation does not affect the position of the HH.

- The relative movement of the $\mathrm{HH}$ is independent from the angle of the plane of elevation.

- The bone segment lengths are proportional to body size. 
- The point motion HH of human arm corresponding to elevation angle $\square_{1}$ is shown in Equations (1-3) and Figure 2.

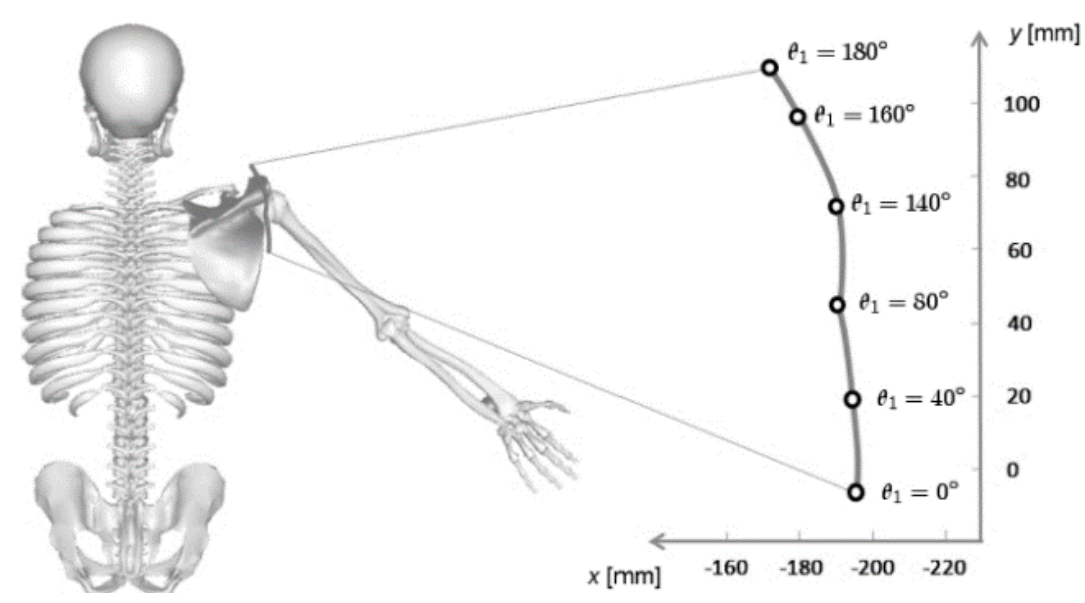

Figure 2:Back View Showing the XY-Position of the HH For Arm Elevation Angle for a Healthy Subject of 1.7 M Body Size [19].
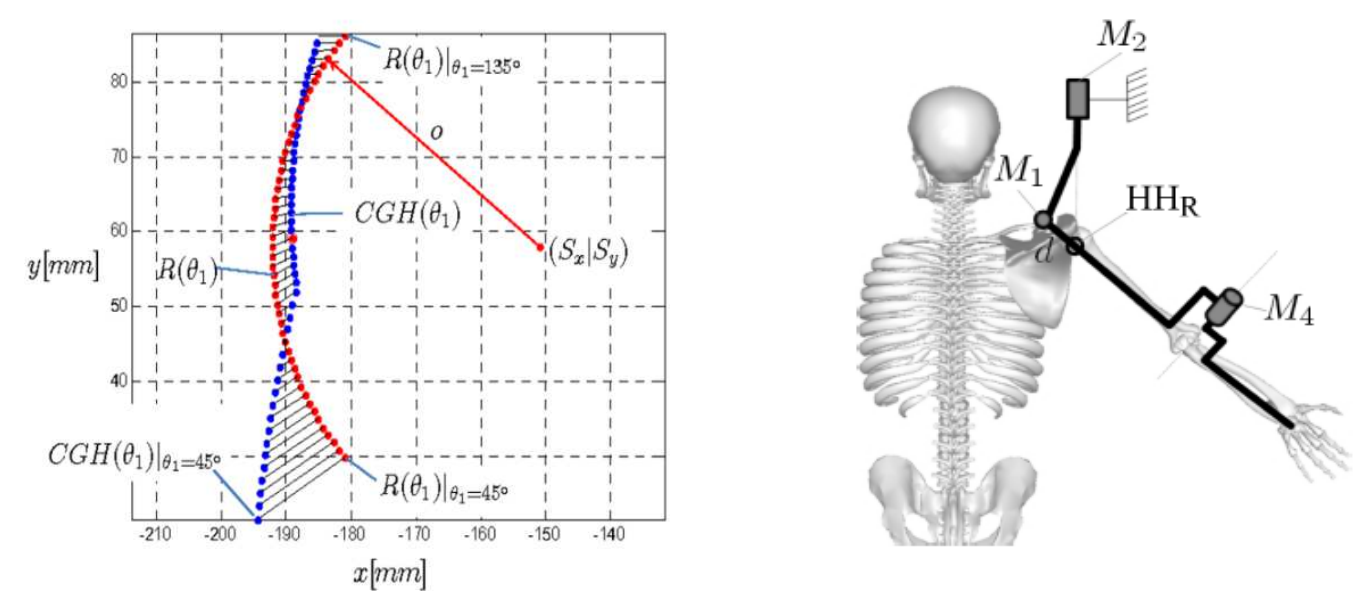

Figure 3: (A) HH Trajectories of Human and Armin III Robot; (B) Kinematic Model of Armin III.
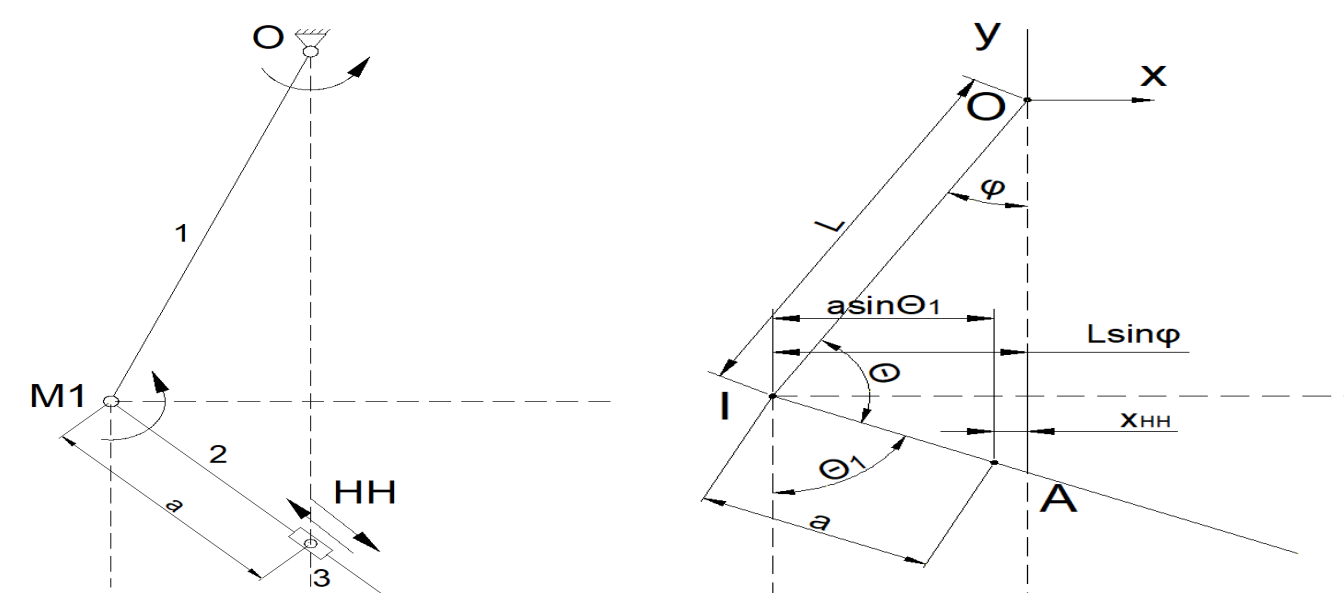

Figure 4: (A) Proposed Principle of Model; (B) Calculating Model.

\subsection{The Proposal Ergonomic Shoulder for Robot}

To design the upper limb rehabilitation robot, the first mission is to find the kinematic structure that replicates as closely as possible the movement of human's HH. One of the very famous solutions isshown in the Armin III robot model. The 
ideais to approximate the natural movement of $\mathrm{HH}$ without robot $\left.\left(\mathrm{HH}_{\mathrm{WR}}\right)\right)$ by an arc of radius $\mathrm{d}$ and center $(\mathrm{Sx}, \mathrm{Sy})$ as shown in Figure 3.a. This is done by deflecting the elevation motor M1 an angle $\square$ as in Figure 3.b. Motor M1 revolves around axis $\mathrm{a}_{1}$ effectelevatedarm, while motor M2revolvesaround center a2 rotate the plane of elevation.

With the above structure, the motion trajectory of $\mathrm{HH}_{\mathrm{WR}}$ has not coincidedwithHH $\mathrm{H}_{\mathrm{R}} \mathrm{In}$ addition, the RoM of the shoulder joint is also limited. The reason the model does not improve ultimately is given to avoid the complexity of the structure.

This study, based on the aboveresults, will make improvements to ensure that the $\mathrm{HH}_{\mathrm{WR}}$ will coincide with the $\mathrm{HH}_{\mathrm{R}}$ as well as expand the range of shoulder joint activity. Besides, the new shoulder structure does not increase the complexity of Armin III's current shoulder structure. The principle diagram of the idea is shown in Figure 4 . HH $\mathrm{H}_{\mathrm{R}} \mathrm{motion}$ trajectory corresponds to the elevation movement of human arm at axis $\mathrm{a}_{1}$ made by coordinating the operation of two motions: Angle-deflection motion $\square$ and translational motion an as Figure 4.

From the calculation model Figure 4.b, somecontraints are as follow :

$$
\begin{aligned}
& 180^{0}=\square_{1}+\square+\square \\
& \mathrm{X}_{\mathrm{HH}}=-\left(\mathrm{L} \cdot \sin (\square)-\mathrm{a} \cdot \sin \left(\square_{1}\right)\right) \\
& \mathrm{Y}_{\mathrm{HH}}=-\left[\mathrm{L} \cdot \cos (\square)+\mathrm{a} \cdot \cos \left(\square_{1}\right)\right]
\end{aligned}
$$

From the aboveequations, the values: $\square \square \square \square \square$ and a are determinedcorresponding to the trajectory of humanarm's HH as in formula (5) and (6).

$$
\left\{\begin{array}{c}
a_{12}=-\left(y \cos \theta_{1}-x \sin \theta_{1}\right) \pm \sqrt{\left(y \cos \theta_{1}-x \sin \theta_{1}\right)^{2}-\left(x^{2}+y^{2}-L^{2}\right)} \\
\varphi=\arcsin \frac{x-a \cdot \sin \theta_{1}}{L} \\
\theta=180^{\circ}-\theta_{1}+\arcsin \frac{x-a \cdot \sin \theta_{1}}{L}
\end{array}\right.
$$

Or:

$$
\left\{\begin{array}{c}
\theta=180^{\circ}-\theta_{1}+\arcsin 180^{\circ}-\theta_{1}+\arcsin \frac{\mathrm{x}-\left[-\left(\mathrm{y} \cos \theta_{1}-\mathrm{x} \sin \theta_{1}\right) \pm \sqrt{\left(\mathrm{y} \cos \theta_{1}-\mathrm{x} \sin \theta_{1}\right)^{2}-\left(\mathrm{x}^{2}+\mathrm{y}^{2}-\mathrm{L}^{2}\right)}\right] \cdot \sin \theta_{1}}{\mathrm{~L}} \\
\varphi=\arcsin \frac{\mathrm{x}-\left[-\left(\mathrm{y} \cos \theta_{1}-\mathrm{x} \sin \theta_{1}\right) \pm \sqrt{\left(\mathrm{y} \cos \theta_{1}-\mathrm{x} \sin \theta_{1}\right)^{2}-\left(\mathrm{x}^{2}+\mathrm{y}^{2}-\mathrm{L}^{2}\right)}\right] \cdot \sin \theta_{1}}{\mathrm{~L}} \\
\theta=180^{\circ}-\theta_{1}+\arcsin \frac{\mathrm{x}-\left[-\left(\mathrm{y} \cos \theta_{1}-\mathrm{x} \sin \theta_{1}\right) \pm \sqrt{\left(\mathrm{y} \cos \theta_{1}-\mathrm{x} \sin \theta_{1}\right)^{2}-\left(\mathrm{x}^{2}+\mathrm{y}^{2}-\mathrm{L}^{2}\right)}\right] \cdot \sin \theta_{1}}{\mathrm{~L}}
\end{array}\right.
$$

\subsection{Optimize the Parameter of the Model}

Based on the formulas (5) and (6), corresponding to each set of input parameters (x,y and $\square_{1}$ ) we will have 2 sets of solutions $(\mathrm{a}, \square, \square)$. Intending to ensure continuity, there is no sudden change between two continuous sets of solutions, from the calculations (5-6), we will find the optimal length $\mathrm{L}$ so that the value of displacement when controlled (a, $\square, \square$ ) is continuous, not subject to sudden changes.

The proposed algorithm is described in Figure 5. Corresponding to each value of $\mathrm{L}$ with a step value of $\Delta \mathrm{L}$, the program will calculate the set of coordinates of the point coordinates $\mathrm{HH}$ of human arm. Corresponding to the coordinates $\left(\mathrm{x}, \mathrm{y}, \square_{1}\right)$, the program solves the set of parameters q of (a, $\left.\square, \square\right)$. Compare to find the smallest value in the values $\delta_{\mathrm{j}}$ will be 
the optimal value. From there, the $\mathrm{L}$ value will be determined.

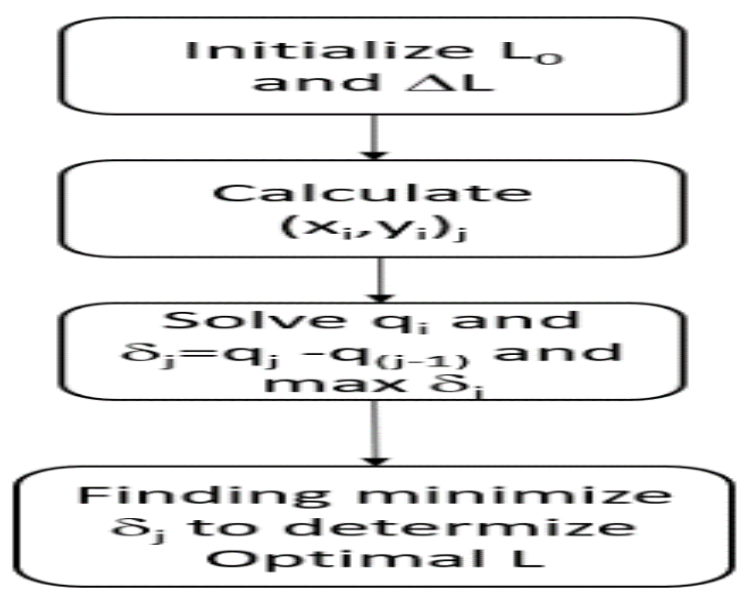

Figure 5: Algorithm to Find the Optimal Length of L.

\section{RESULTS}

Through the process of running the algorithm, we determine the solution as follows:

$$
L_{\text {opt }}=206.83 \text { corresponds with biggest step of } \Delta \mathrm{a}_{\max }=2.62 \Delta \square_{\max }=0.93^{0}
$$

To retest the set of solutions $(\mathrm{a}, \square, \square)$ for the point trajectory of $\mathrm{HH}_{\mathrm{R}}$ corresponding to the optimal value of $\mathrm{L}$ above, we will apply the forward kinematic problem to conduct the retest. First of all, the endpoint coordinates are determined by the transformation of the homogeneous coordinates of the end-effector (point $\mathrm{HH}_{\mathrm{R}}$ ) by the component links: Running the calculation program, we have the graph of the orbital point HH robot as Figure 7. This shows that the ROM of the proposed mechanism for shoulder's robot has full RoM compared to human movement. This will help the upper limb rehabilitation robot, which not only creates comfort for the patient's shoulder joint when manipulated thanks to the robot's shoulder joint that coincides with the human shoulder joint but also expands the

Working space of the patient's Arm. This is important because the shoulder joint can be considered as the root in a serial system if the RoM of the shoulder joint is extended, the working space will also be significantly expanded.

In order to compare the deviations between $\mathrm{HH}_{\mathrm{WR}}$ and $\mathrm{HH}_{\mathrm{R}}$, we use the average square deviation between the points calculated from the proposed model with the corresponding points in the orbit of the HH of the human arm. The calculation formula is expressed as the formula (1314).

Through the calculation process, it is easy to see that the trajectory of robot's shoulder joint $\mathrm{HH}_{\mathrm{R}}$ robot is identical to the $\mathrm{HH}_{\mathrm{WR}}$ shoulder trajectory. This is shown, as shown in Figure 6. It is also more clearly quantified through the values in formulas (13) and (14). The total deviations in the $\mathrm{x}$ and $\mathrm{y}$ directions between the HH of human arm's shoulder and proposed robot trajectories are $0.0028 \mathrm{~mm}$ and $0.0115 \mathrm{~mm}$, respectively.

In summary, the table comparing the parameters between the proposing shoulder joint structure models for the upper limb rehabilitation robot (UExosVN) with the model of Armin III is shown in Table 1. The detailed structure of the proposed model described as Figure 7. In this design, instead of using 2 passive joints (P1 and P2) as in Figure 7.a, the proposed model uses 2 active joints of A2 and A4 as in Figure 7.b. The new design does not make the system much more complex but increase the mass around $1.6 \mathrm{Kg}$. 


$$
\begin{aligned}
& A_{-} 01=\left[\begin{array}{cccc}
\cos \varphi & -\sin \varphi & 0 & \mathrm{~L}^{*} \cos \varphi \\
\sin \varphi & \cos \varphi & 0 & \mathrm{~L}^{*} \sin \varphi \\
0 & 0 & 1 & 0 \\
0 & 0 & 0 & 1
\end{array}\right] \\
& \mathrm{A}_{-} 12=\left[\begin{array}{cccc}
\cos \theta_{1} & -\sin \theta_{1} & 0 & \mathrm{~L}_{1} * \cos \theta_{1} \\
\sin \theta_{1} & \cos \theta_{1} & 0 & \mathrm{~L}_{1} * \sin \theta_{1} \\
0 & 0 & 1 & 0 \\
0 & 0 & 0 & 1
\end{array}\right] \\
& \mathrm{A}_{-} 23=\left[\begin{array}{cccc}
0 & 0 & -1 & 0 \\
1 & 0 & 0 & 0 \\
0 & -1 & 0 & 0 \\
0 & 0 & 0 & 1
\end{array}\right] \\
& \mathrm{A}{ }_{-} 34=\left[\begin{array}{cccc}
1 & 0 & 0 & 0 \\
0 & 1 & 0 & 0 \\
0 & 0 & 1 & \mathrm{a}_{3} \\
0 & 0 & 0 & 1
\end{array}\right]
\end{aligned}
$$

With:

- L: Length of the deflected bar.

- $\mathrm{L}_{1}$ : Length of changing distance a link.

- $\mathrm{a}_{3}$ : Distance from endpoint of length alignment to HH robot point.

Matrix uniform homogeneous transformation between manipulation and fixed links:

$$
\operatorname{Ar}=\left[\begin{array}{cccc}
-\sin \left(\varphi+\theta_{1}\right) & 0 & -\cos \left(\varphi+\theta_{1}\right) & \mathrm{L}_{1} * \cos \left(\varphi+\theta_{1}\right)-\mathrm{a}_{3} * \cos \left(\varphi+\theta_{1}\right)+\mathrm{L} * \cos (\varphi) \\
\cos \left(\varphi+\theta_{1}\right) & 0 & -\sin \left(\varphi+\theta_{1}\right) & \mathrm{L}_{1} * \sin \left(\varphi+\theta_{1}\right)-\mathrm{a}_{3} * \sin \left(\varphi+\theta_{1}\right)+\mathrm{L} * \sin (\varphi) \\
0 & -1 & 0 & 0 \\
0 & 0 & 0 & 1
\end{array}\right]
$$

And coordinate of $\mathrm{HH}_{\mathrm{R}}$ :

$$
\begin{aligned}
& \mathrm{x}=\mathrm{L}_{1} * \cos \left(\varphi+\theta_{1}\right)-\mathrm{a}_{3} * \cos \left(\varphi+\theta_{1}\right)+\mathrm{L}^{*} \cos (\varphi) \\
& \mathrm{y}=\mathrm{L}_{1} * \sin \left(\varphi+\theta_{1}\right)-\mathrm{a}_{3} * \sin \left(\varphi+\theta_{1}\right)+\mathrm{L}^{*} \sin (\varphi) \\
& \Delta \mathrm{x}=\sqrt{\left(\mathrm{x}_{1}-\mathrm{x}_{1}^{\prime}\right)^{2}+\left(\mathrm{x}_{2}-\mathrm{x}_{2}^{\prime}\right)^{2}+\ldots+\left(\mathrm{x}_{\mathrm{n}}-\mathrm{x}_{\mathrm{n}}^{\prime}\right)^{2}}=0.0028 \mathrm{~mm} \\
& \Delta \mathrm{y}=\sqrt{\left(\mathrm{y}_{1}-\mathrm{y}_{1}^{\prime}\right)^{2}+\left(\mathrm{y}_{2}-\mathrm{y}_{2}^{\prime}\right)^{2}+\ldots+\left(\mathrm{y}_{\mathrm{n}}-\mathrm{y}_{\mathrm{n}}^{\prime}\right)^{2}}=0.0115 \mathrm{~mm}
\end{aligned}
$$




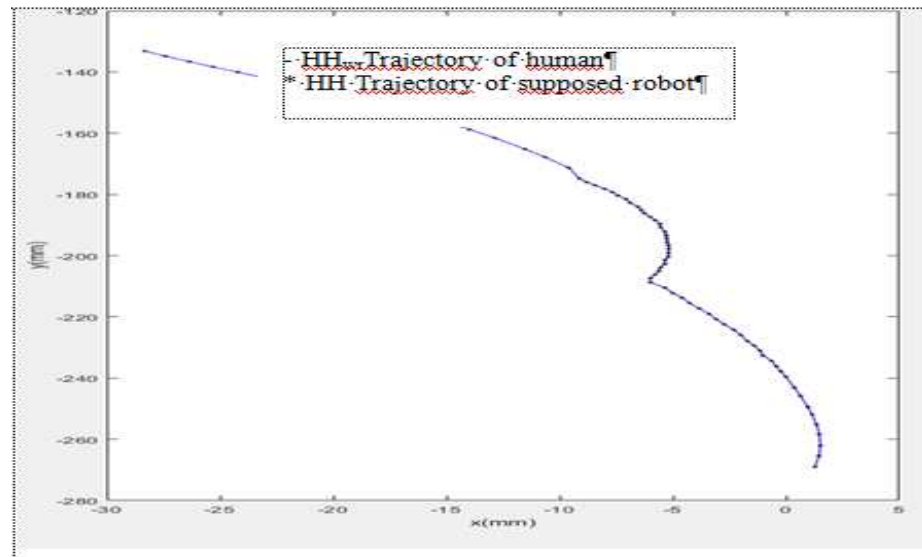

Figure 6. Simulation Result.

Table 1: Comparison Between Shoulder Model of Armin III And Proposed UExosVN

\begin{tabular}{|c|c|c|c|c|}
\hline Models & DoFs & Arm Elevation RoM & HH vs. HH & Mass \\
\hline Armin III & $3 \mathrm{~A}+2 \mathrm{P}$ & $45^{0} \leq \square_{1} \leq 135^{0}$ & Approximate & $\approx 15 \mathrm{~kg}$ \\
\hline UExosVN & $5 \mathrm{~A}$ & $0^{0} \leq \square_{1} \leq 180^{0}$ & The same & $16,6 \mathrm{~kg}$ \\
\hline
\end{tabular}

A: Active joint; P: Passive joint
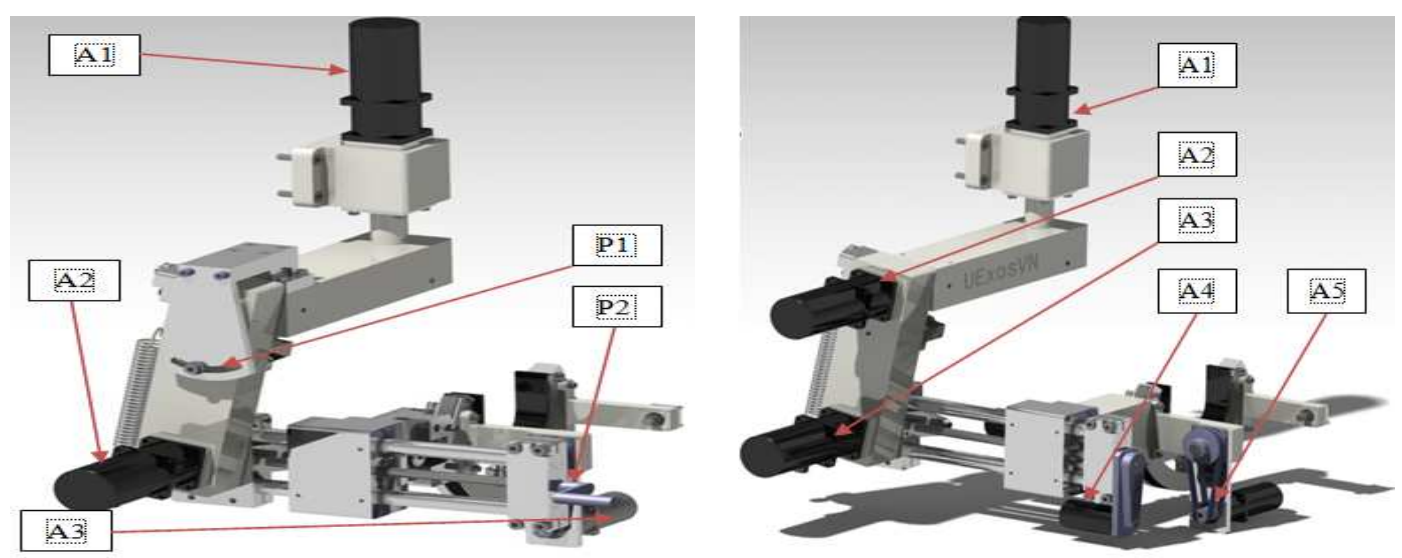

Figure 7: Shoulder Joint 3D Model of Armin III and Proposed UExosVN Robots.

(A) Shoulder Model of ARMIN III Robot.

(B) Proposed Shoulder Model of UExosVN Robot.

\section{CONCLUSIONS}

In this study, a new shoulder joint model for the upper limb exoskeleton robot was proposed. The newly created shoulder joint model comes from the Armin III shoulder joint model which attached more 2 DoFs but does not complicate the device's structure too much. With the proposed model, the process of optimizing the model's geometry parameters has been implemented to ensure the movement of the points in the trajectory of the HH points continuously and without sudden changes when co-operating control of deflection actuator, elevation actuator and length adjustment actuator. The proposed structure ensures robot's shoulder trajectory coincides with the human shoulder joint trajectory during movement, and the ranges of motion are the same.

\section{REFERENCES}

1. Brainin M, Bornstein N, Boysen G, Demarin V. 2000. Acute neurological stroke care in Europe: results of the European stroke care inventory. Eur J Neurol. 7:5-10. 
2. Rosamond W, Flegal K, Friday G, Furie K, Go A, Greenlund K, Haase N, Ho M, Howard V, Kissela B, Kittner S, LloydJonesD, McDermott M, Meigs J, Moy C, Nichol G, O’Donnell CJ, Roger V, Rumsfeld J, Sorlie P, Steinberger J, Thom T, Wasserthiel-Smoller S, Hong Y; American Heart Association Statistics Committee and Stroke Statistics Subcommittee.2007. Heart disease and stroke statistics-2007 update: a report from the American Heart Association Statistics Committee and Stroke Statistics Subcommittee. Circulation. 115(5):e69- 171. Epub 2006 Dec. 28.

3. RAJALAXMI, $V$., et al. "EFFECTIVENESS OF CONSTRAINT INDUCED MOVEMENT THERAPY IN COMPARISION WITH TRADITIONAL REHABILITATION THERAPY IN TREATING UPPER EXTREMITY OF THE ACUTE AND SUBACUTE STROKE PATIENTS." (2008).International Journal of Physiotherapy \& Occupational Therapy (TJPRC: IJPOT). 2. 2, Dec $2016,174$.

4. Platz T. 2003. Evidenzbasierte armrehabilitation: Eine systematische literatur ubersicht. Nervenarzt 74:841-849.

5. Kwakkel G, Wagenaar RC, Twisk JWE, Langkhorst GJ, Koetsier JC. 1999. Intensity of leg and arm training after primary middle-cerebral artery stroke: a randomized trial. Lancet 35:191-196.

6. KRISHNA, VINAY, et al. "CERVICAL SYMPATHECTOMY FOR HYPERHIDROSIS: A REPORT OF TWO CASES. "International Journal of Medicine and Pharmaceutical Science (IJMPS) 7. 5, Oct 2017, 914.

7. Bayona NA, Bitensky J, Salter K, Teasell R. 2005. The role of task-specific training in rehabilitation therapies. Top Stroke Rehabil. 12:58-65.

8. Riener R, Lüunenburger L, Jezernik S, Anderschitz M, Colombo G, Dietz V. 2005a. Cooperative subject-centered strategies for robot-aided treadmill training: first experimental results. IEEE Trans Neural Syst Rehabil Eng. 13:380-393.

9. ARULSINGH, WATSON, and GANESH S. PAI. "DOES THE INCIDENCE OF ACQUIRED HALLUX VALGUS VARY FROM SHOD RUNNERS TO BAREFOOT RUNNERS?-A COMPARATIVE STUDY."TJPRC:International Journal of Physiotherapy \& Occupational Therapy (TJPRC:IJPOT) 2, Dec 2015, 17-28.

10. Nef T, Mihelj M, Riener R. 2007a. ARMin: a robot for patientcooperative armtherapy.Med Biol Eng Comput. 45:887-900.

11. Trung NGUYEN, Dung NGUYEN and Hung DAO, "Design and Manufacture Wire-driven device to Support Upper Limbs Rehabilitation”, 2019 KICS Korea-Vietnam International Joint Workshop on Communications and Information Sciences, ISSN/ISBN: 978-89-950043-7-1 [93560], 20-22/11/2019, HUST, Hanoi, Vietnam.

12. Krebs HI, Ferraro M, Buerger SP, Newbery MJ, Makiyama A, Sandmann M, LynchD, Volpe BT,HoganN. 2004. Rehabilitationrobotics: pilot trial of a spatial extension forMIT-Manus. J Neuroeng Rehabil. 1:5.

13. Lum PS, Burgar CG, Shor PC. 2004. Evidence for improved muscle activation patterns after retraining of reaching movements with the MIME robotic system in subjects with poststroke hemiparesis. IEEE Trans Neural Syst Rehabil Eng. 12(2):186-94.

14. Napolitano, Salvatore, and Antonio Ascione. "Performance Posture Correlation: A Study in the Women's Water Polo." International Journal of Humanities and Social Sciences (IJHSS) 6.6 (2017): 53-62.

15. Trung Nguyen, Hung Dao, Takashi Komeda, A Novel Active Ankle Orthosis System: Idea and Design, 2014 International Conference on Mechatronics and Mechanical Design, Paper No. F021,26-28 Dec, 2014.

16. Kim, S.; Nussbaum, M.A.; Esfahani, M.I.M.; Alemi, M.M.; Jia, B.; Rashedi, E. Assessing the influence of a passive, upper extremity exoskeletal vest for tasks requiring arm elevation: Part II- "Unexpected" effects on shoulder motion, balance, and spine loading. Appl. Ergon. 2018, 70, 323-330.

17. Bianchi, M.; Fanelli, F.; Conti, R.; Governi, L.; Meli, E.; Ridolfi, A.; Rindi, A.; Vannetti, F.; Allotta, B. Design and Motion Analysis of a Wearable and Portable Hand Exoskeleton. In Wearable Robotics: Challenges and Trends, Proceedings of the 
2nd International Symposium on Wearable Robotics, Segovia, Spain, 18-21 October, 2016; Springer: Berlin, Germany, 2016; pp. 373-377.

18. Staubli, P.; Nef, T.; Klamroth-Marganska, V.; Riener, R. Effects of intensive arm training with the rehabilitation robot ARMin II in chronic stroke patients: Four single-cases. J. Neuroeng. Rehabil. 2009, 6, 46. doi:10.1186/1743-0003-6-46.

19. Tröster, M.; Schneider, U.; Bauernhansl, T.; Rasmussen, J.; Andersen, M.S. Simulation Framework for Active Upper Limb Exoskeleton Design Optimization Based on Musculoskeletal Modeling. Available online: https://vbn.aau.dk/ws/portalfiles/portal/292649860/M.Tr_ster_SmartASSIST_2018_02112018_Paper_32.pdf (accessed on 4 February 2020).

20. Stienen, A.H.; Hekman, E.E.; Van Der Helm, F.C.; Van Der Kooij, H. Self-aligning exoskeleton axes through decoupling of joint rotations and translations. IEEE Trans. Robot. 2009, 25, 628-633.

21. Hsieh, H.C.; Chen, D.F.; Chien, L.; Lan, C.C. Design of a Parallel Actuated Exoskeleton for Adaptive and Safe Robotic Shoulder Rehabilitation. IEEE/ASME Trans. Mechatron. 2017, 22, 2034-2045.

22. Perry, J.C.; Trimble, S.; Machado, L.G.C.; Schroeder, J.S.; Belloso, A.; Rodriguez-de Pablo, C.; Keller, T. Design of a springassisted exoskeleton module for wrist and hand rehabilitation. In Proceedings of the 38th Annual International Conference of the IEEE Engineering in Medicine and Biology Society (EMBC), Orlando, FL, USA, 16-20 August 2016; pp. 594-597.

23. Tobias Nef Marco Guidali and Robert Riener, ARMin III - arm therapy exoskeleton with an ergonomic shoulder actuation, Applied Bionics and Biomechanics Vol. 6, No. 2, June 2009, 127-142.

24. Sanchez RJ, Liu J, Rao S, Shah P, Smith R, Rahman T, Cramer SC, Bobrow JE, Reinkensmeyer DJ. 2006. Automating arm movement training following severe stroke: functional exercises with quantitative feedback in a gravity-reduced environment.IEEE Trans Neural Syst Rehabil Eng. 14(3):378-389.

25. Tobias Nef, Robert Riener, ARMin - Design of a Novel Arm Rehabilitation Robot, 9th International Conference on Rehabilitation Robotics, pages (5760).

26. Stienen AHA, Hekman EEG, Van der Helm FCT, Prange GB, Jannink MJA, Aalsma AMM, Van der Kooij H. 2007. Dampace: dynamic force-coordination trainer for the upper extremities. Proceedings of the IEEE 10th International Conference on Rehabilitation Robotics; June 13-15; Noordwijk, The Netherlands, pp. 820-826. 